\title{
Development of Structural Dynamic Analysis Software of Truss Structure Using Monte Carlo Finite Element Method
}

\author{
Muhammad Ichsan $^{1, *}$, Handayanu ${ }^{2}$ and Agro Wisudawan ${ }^{2}$ \\ ${ }^{1}$ Ocean Engineering Department of ITS, Undergraduate Student, 60111 Surabaya, Indonesia \\ ${ }^{2}$ Ocean Engineering Department of ITS, Lecturer, 60111 Surabaya, Indonesia
}

\begin{abstract}
Structural reliability analysis is increasingly used in conjunction with the design of offshore structures which have high uncertainty. Two problems i.e. reliability and complexity of the structures resulted in Monte Carlo Finite Element Method (MCFEM) method of analysis. In the first part of this research, we will show results comparison between deterministic analysis software made in Proposed Software and analysis using commercial established software. In this case, object will assume as a simple Plane Truss structure with multi degrees of freedom applied dynamic load in the support of structure. The second part after obtaining a deterministic result compared by commercial software, further we will apply MCFEM algorithm to the deterministic analysis algorithm which has been made. The results of this research, contains a new procedure in the form of reliability simulation algorithm by combining Monte Carlo Simulation and Finite Element Method in Dynamic Model.
\end{abstract}

\section{Introduction}

Structural design should involve a various random variables both demand side such as environmental load, live load, etc. and supply side such as material strength, dimension, etc. In order to explain this random behaviour, statistics or probabilistic methods should be used [1].

In traditional structural analysis, structural strength and load will be simplified as the "maximum" (load) and the "minimum" (strength) which are largely based on deterministic data. This approach is not relevant since random behaviour of some structures are increase.

Some researchers have attempted to derive equations to predict these random variables in term of stochastic approach [2]. This approach will be a new reference to structural design procedure.

In the other hand, the complexity of structural geometry is not possible to be analyzed by using manual calculations. So, another helpful way to solve it, is by using computer-aided calculations which is known as numerical simulation [3].

The most widely used numerical method today is Finite Element Methods, but this method is limited to deterministic parameters used only [4]. Thus, to overcome this limitation, researchers try to combine finite element analysis and statistical methods to obtain efficient and effective results [5].

One of statistical method developed to solve random variables is Monte Carlo analysis [6] which is applied in deterministic analysis.

*Corresponding author: ichsan.celebes@gmail.com 
On that background this research will discuss about Dynamic analysis on Simple Plane Truss structure by using Monte Carlo Finite Element Method Simulation.

In numerical computational analysis and design in science applications are known a lot of software such as Maple, Mathematica, Maxima, and so on. But at time went on Matlab came to dominate the market [7].

\section{Research Description}

In this study, the first attempt was to find relevant literature related to Monte Carlo, Finite Element Method on Dynamic of Structure, Proposed Software usage for finite element analysis, etc. Based on literature study, a dynamic displacement model calculation algorithm is created. Flowchart is a procedure that describes the steps of workflow in the form of flow diagrams. Flowchart calculations will be used to compile the function listings in Proposed Software.

After the displacement results in Proposed Software are known, then we will have performed the same analysis on the commercial established software to compare the results of previous calculations on the proposed software.

The creation of dynamic model analysis flowchart which is applied in Monte Carlo Finite Element Method then subsequently carried by forming Monte Carlo methods listing which will be added to the listing of displacement analysis of dynamic models that have been made previously.

After the analysis and determination are finished, it will be deduced from the problem and the previous goal to show how much structure reliability of the dynamic analysis are performed.

\section{Result and Discussion}

\subsection{Reliability Analysis by using Monte Carlo Simulation and Finite Element Method on Dynamic Model Algorithm}

Based on the results of literature study and review related to dynamic model structure analysis which will be applied Monte Carlo method, it is necessary some stage in determining the movement in the dynamic model structure of a simulation, such as determining the structure configuration based on the desired element type, perform the modal analysis and determine the method which is used in completing the dynamic model motion equation.

In the early stages, determine the distribution of random parameters which is used in the simulation process, as in Figure 1 random parameter consist of Young's modulus $(E)$, Additional Mass $\left(M_{a d d}\right)$, and Control Displacement $\left(u_{c}\right)$.

After random variable is input, it must be repeated as much as the predetermined iteration by calling to 3 random parameters previously. Then, these 3 parameters are transformed to new variables $E, M_{a d d}$, and $u_{c}$ which are used as inputs in calculations of simple Plane Truss Structures.

Dynamically model which is analyzed has assumption that acceleration happening in the support of the structure. Since real case known, a dynamic model analysis involves a fairly complex $p(\tau)$ function, the solution of the dynamic model equation uses the time history method with the completion of numerical techniques which is used the Newmark Method $[8]$.

After the result is found as a displacement that occurs on each joint, it will be identified whether the element fails or not. The identification will be done by using Serviceability 


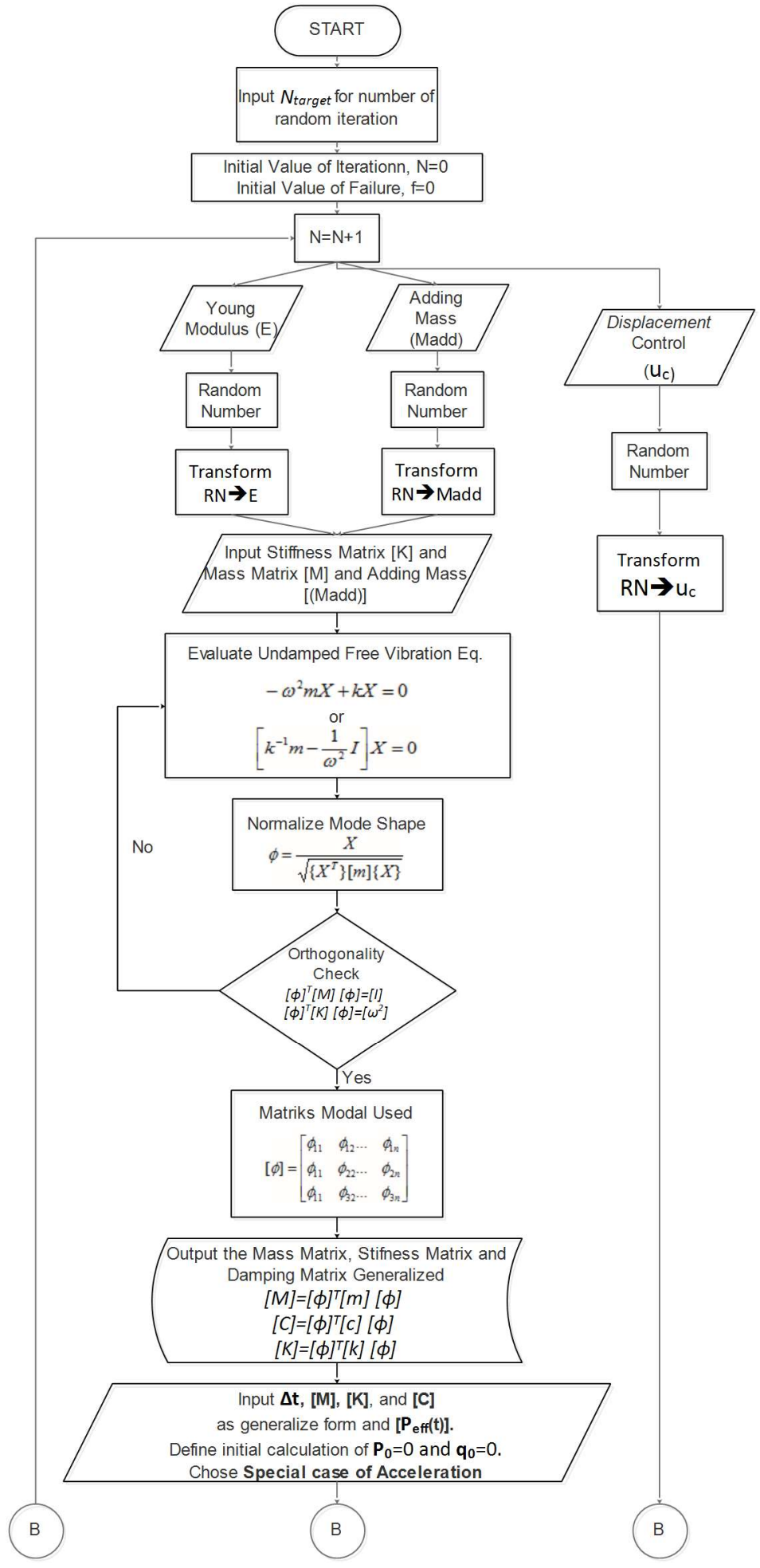

Fig. 1. Dynamic Model MCFEM Algorithm 


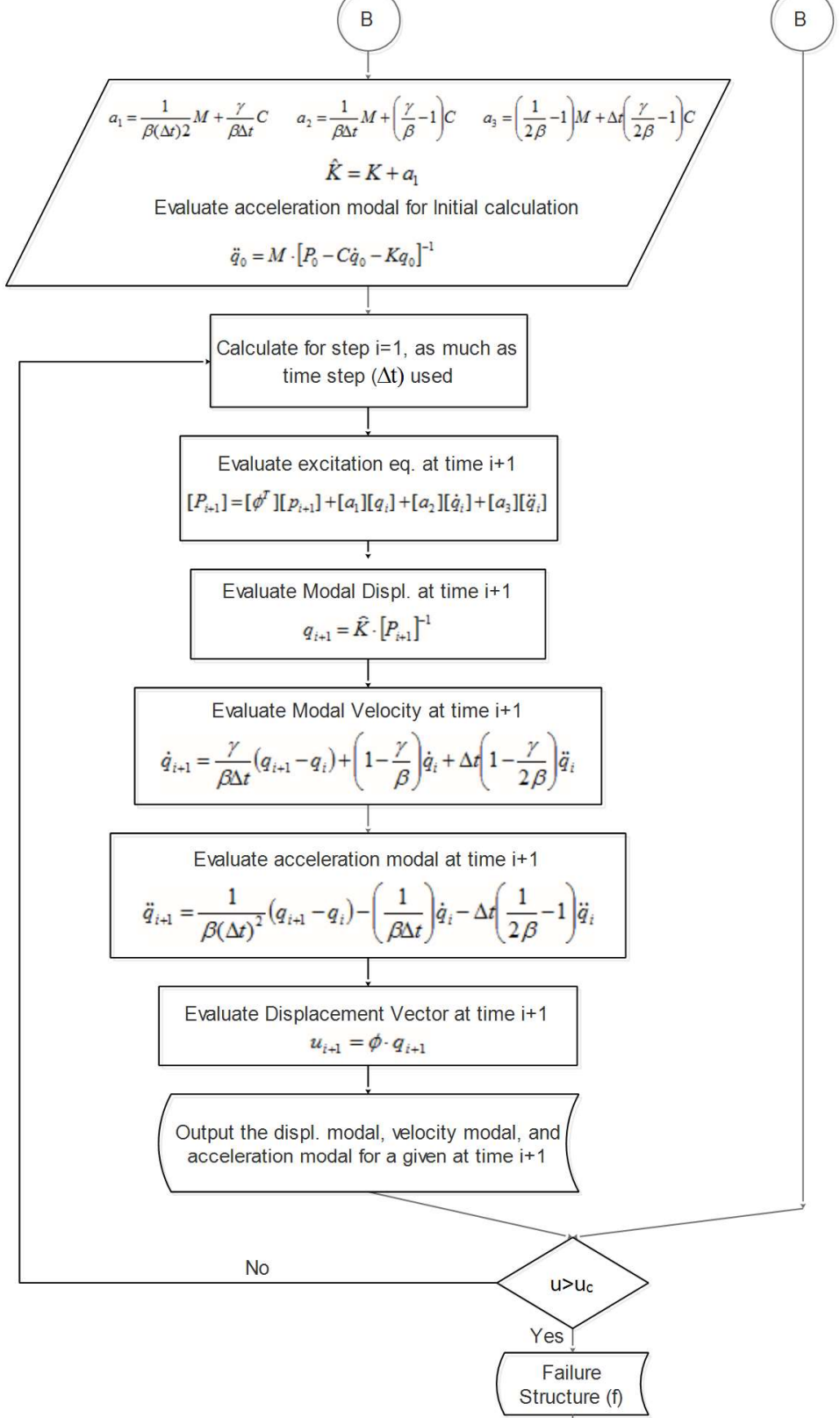

Yes
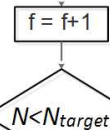

No

Calculate

$\mathrm{Pof}=\mathrm{g} / \mathrm{N}$

STOP

Fig. 1. Dynamic Model MCFEM Algorithm (Continued) 
Limit State (SLS) method, the SLS provides the criterion that the structure keep standing with small earthquake intensity without getting damage [9] by using failure modes $M K(X)$ as follows:

or

$$
M K(X) \leq 0
$$

$$
\Delta \mathrm{u}_{\mathrm{e}} \leq\left[\theta_{e}\right] h \text { or }\left[\theta_{e}\right] h-\Delta \mathrm{u}_{\mathrm{e}} \geq 0
$$

or

$$
u_{\text {actual }}-u_{\text {control }} \leq 0
$$

The equation 1-3 will be used for probability of failure calculation $\left(P_{f}\right)$ as much as the predetermined simulation by using the equation below:

$$
P_{f}=\frac{N_{f}}{N}
$$

The number of failures $\left(N_{f}\right)$ will be recorded for each $M K(X)<0$ and this simulation will be repeated as much as simulation $(N)[10]$.

By $P_{f}$ obtained, it can be determined the reliability of each displacement joint which is reviewed by using the equation below:

$$
R=1-P_{f}
$$

\subsection{Monte Carlo App and Finite Element Method on Dynamic Model}

There are several function listings module used in this research are:

a. Listing Function of Truss Element Stiffness

This function is used to determine the stiffness matrix of plane truss element on each element. The inputs to this function are Young's Modulus (E), cross sectional area (A), element length (L), and inclination angle.

b. Listing Function of the Truss Element Mass

In this study the mass matrix is assumed to be lumped parameter matrix (mass concentrated at each node). The input required in this function is the density, crosssectional area and bar length.

c. Listing Function of Matrix Assembly

The assembly matrix listing is used to superimpose all elements of the stiffness matrix and the mass matrix of the structure into one stiffness matrix and one mass matrix only. The input of the above function is a zero matrix of size corresponding to the number of nodes, the stiffness matrix and the mass matrix of each element and the node which form elements ( $\mathrm{i}$ and $\mathrm{j}$ ).

d. Listing Function of Modal Analysis

Listing function is used to determine the natural frequency and shape modes of the model. The input of this listing is the mass matrix and the stiffness that is already in the form of matrix assembly and boundary conditions.

e. Acceleration type selection

Listing function is used to determine the type of acceleration desired based on the suitability of the data. The selection is between choosing "average" or "linear"

f. Listing Initial Condition

Listing function is used to determine the initial condition to be included in the time step process

This stage is divided into several parts, namely:

- Determine time step $(\Delta t)$ used as based on the measurement data in the field of earthquake acceleration that occurred. 
- Determination of initial conditions on values q0, , , U0, and P0.

- Determination, $\gamma$ and $\beta$ constants which follows the type of acceleration specified in the beginning.

g. Listing of time step calculation by using Newmark method.

h. Listing of Reliability Analysis

In this listing will be calculated the number of failures that occur for every simulation as much as the predefined simulation iteration.

\subsection{Monte Carlo App and Finite Element Method on Dynamic Model}

Software comparison done to find out how accurate the calculation of the simulation is, by comparing the proposed software with commercial software.

The model shown will be 2-dimensional simple Plane Truss by using lumped mass matrix.

Figure Model 1 is as follows:

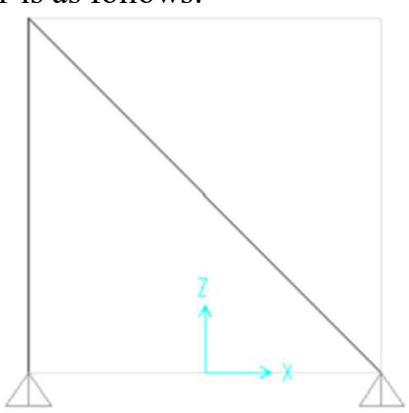

(a)

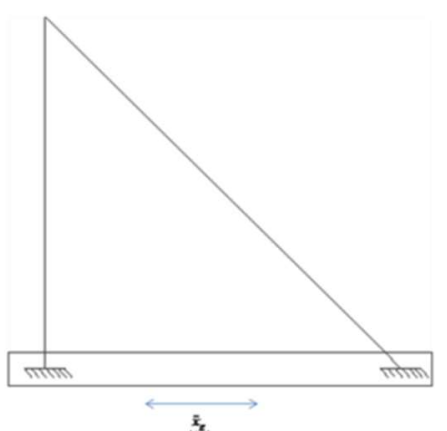

(b)

Fig. 2. Plane Truss Triangle Model

Representation of model shown above in the matrix is depicted in table 1 below:

Table 1. Relevant Parameters of Plane Truss Triangle Model

\begin{tabular}{|c|c|}
\hline Mass Matrix, $\boldsymbol{M}$ & $\boldsymbol{M}=(\mathbf{1 . 0} \boldsymbol{e}+\mathbf{0 5}) \times\left[\begin{array}{ll}1 & 0 \\
0 & 1\end{array}\right]$ \\
\hline Matrix Damping, $\boldsymbol{C}$ & $\boldsymbol{C}=\left[\begin{array}{cc}0.6404 & 0 \\
0 & 0.6404\end{array}\right]$ \\
\hline Stress matrix, $\boldsymbol{K}$ & $\boldsymbol{K}=\left[\begin{array}{cc}81.0270 & 0 \\
0 & 492.4916\end{array}\right]$ \\
\hline $\begin{array}{c}\text { Location of Influence } \\
\text { Vector, } \boldsymbol{r}\end{array}$ & $\boldsymbol{r}=\left[\begin{array}{ll}1 & 0\end{array}\right]$ \\
\hline
\end{tabular}

The structure and acceleration properties of the analysis are as follows:

Table 2. Model Properties Triangle Truss Plane Material

\begin{tabular}{|l|c|}
\hline \multicolumn{1}{|c|}{ Variables } & Value \\
\hline Young Modulus (E) & $29000000 \mathrm{lb} / \mathrm{in}^{2}$ \\
\hline Diameter (D) & $12.3 \mathrm{in}$ \\
\hline Horizontal Element Length (L1) & $118.11 \mathrm{in}$ \\
\hline Diagonal Element Length (L2) & $167.0328 \mathrm{in}$ \\
\hline Mass type ( $\boldsymbol{\rho})$ & $0.7 \mathrm{lb} / \mathrm{in}^{3}$ \\
\hline Additional Mass $\left(\mathbf{M}_{\text {add }}\right)$ & $100000 \mathrm{lb}$ \\
\hline
\end{tabular}




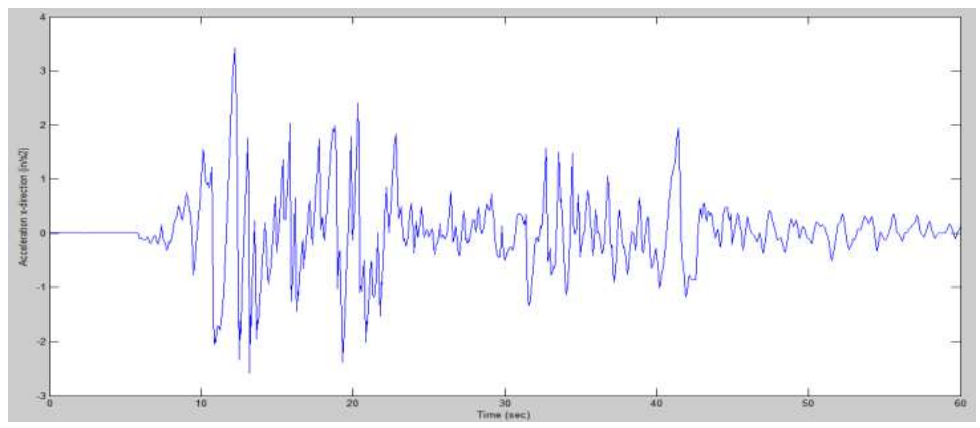

Fig. 3. Acceleration that occurs on the support of structure

The results of dynamic model analysis on the structure plane truss triangle model then compared each other. The comparisons are shown in table 3, table 4 and figure 4 below:

Table 3. Comparison of Natural Frequency Results between proposed software and commercial software

\begin{tabular}{|c|c|c|c|c|c|}
\hline & Mode & Proposed Software & $\begin{array}{c}\text { Commercial } \\
\text { Software }\end{array}$ & $\Delta$ (Error) & Unit \\
\hline $\begin{array}{c}\text { Natural } \\
\text { Frequency }\end{array}$ & 1 & 9.001500 & 9.001500 & $0.000002 \%$ & \multirow{2}{*}{$\mathrm{rad} / \mathrm{s}$} \\
\cline { 2 - 5 } & 2 & 22.192151 & 22.192000 & $0.000681 \%$ & \\
\hline
\end{tabular}

Table 4. Comparison of Maximum Displacement results between proposed software and commercial software

\begin{tabular}{|c|c|c|c|c|c|c|c|}
\hline & Propose & Software & Commerc & Software & \multirow{3}{*}{\multicolumn{2}{|c|}{$\Delta$ (Error) }} \\
\hline & & \multicolumn{4}{|c|}{ (in) } & & \\
\hline & & $\mathbf{U x}$ & $\mathbf{U z}$ & $\mathbf{U} \mathbf{x}$ & $\mathbf{U z}$ & & \\
\hline \multirow{2}{*}{ Dipl. } & Max & $9.86 \mathrm{E}-02$ & $3.22 \mathrm{E}-02$ & $9.01 \mathrm{E}-02$ & $2.95 \mathrm{E}-02$ & $8.532 \%$ & $8.380 \%$ \\
\hline & Min & $-7.90 \mathrm{E}-02$ & $-2.28 \mathrm{E}-02$ & $-7.31 \mathrm{E}-02$ & $-2.13 \mathrm{E}-02$ & $7.453 \%$ & $6.372 \%$ \\
\hline
\end{tabular}

Comparison of displacement graph shown in the picture below:

\section{Displ. x-direction node 2 (in)}

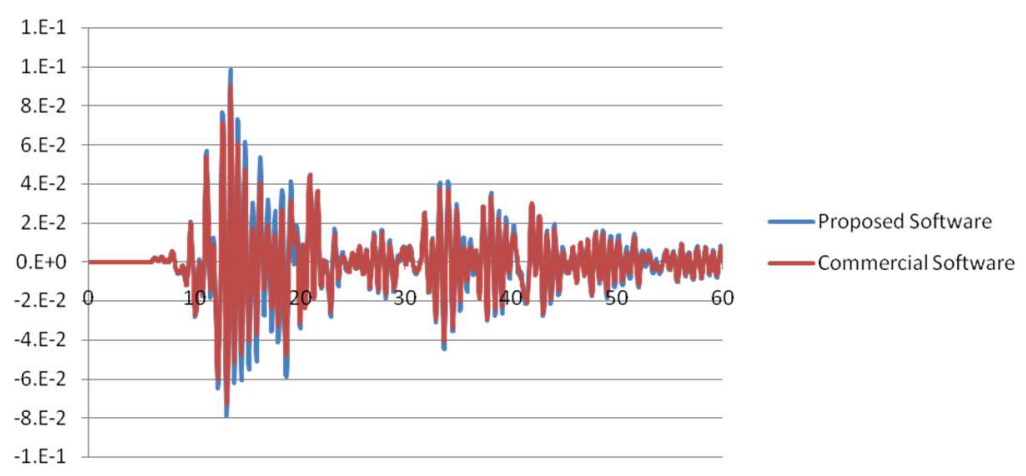

(a) 
Displ. z-direction node 2 (in)

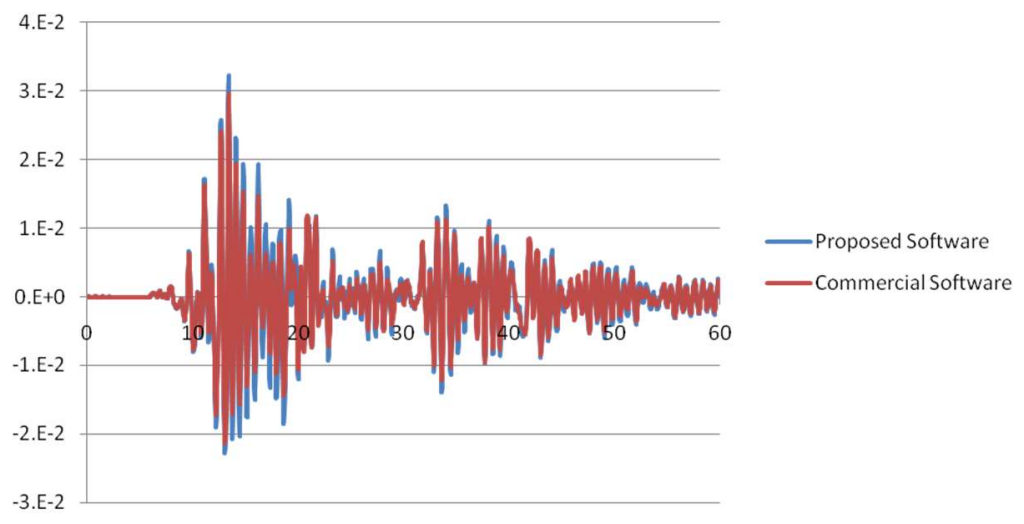

(b)

Fig. 4. Graph of Comparison Displacement node 2 (a) On the $x$-axis and (b) On the z-axis

The presented tables show that the differences between proposed software and commercial software are tolerable.

\subsection{MCFEM application on Dynamic Model}

In this steps, the reliability analysis by using Monte Carlo Finite Element Method is presented to Plane truss triangle model. The suggested simulation refers to Probability of Failure $\left(P_{f}\right)$ [11] where the scale possible at the limit of failure does not occur at $10^{-5}$ otherwise according to [12] this simulation will be stopped if it meets the condition of convergence set $(\varepsilon)$ that is shown in equations 6 and 7 below:

$$
\begin{gathered}
\frac{\left(u_{x i}+1\right)-u_{x i}}{u_{x i}} \times 100 \% \leq 0.006 \% \\
\frac{\left(R_{i}+1\right)-R_{i}}{R_{i}} \times 100 \% \leq 0.6 \%
\end{gathered}
$$

Computer specifications used will affect the running time during simulation, while the simulation in this study will be done with a computer that has the following basic specifications:

$\checkmark$ Processor $=$ Intel@ Core TM i5 CPU @ 3.20 GHz

$\checkmark$ RAM $=4.00 \mathrm{~GB}$

$\checkmark$ Operating System $=$ Windows 8, 64-bit

\subsection{Reliability Analysis Results}

Plane Truss triangle model Structure in figure. 2 will be calculated by use the mechanical properties as follows: 
Table 5. Mechanical Properties on Plane Truss Triangle Model Structure

\begin{tabular}{|c|c|c|c|}
\hline Variable Input & Mean & COV & Distribution \\
\hline Young Modulus $(\boldsymbol{E})$ & $29000000 \mathrm{lb} / \mathrm{in}^{2}$ & 0.075 & Normal \\
\hline Yield Strength $\left(\sigma_{\boldsymbol{y}}\right)$ & $39600 \mathrm{psi}$ & 0.078 & Normal \\
\hline Displacement Control $\left(\boldsymbol{u}_{\boldsymbol{c}}\right)$ & $0.161281241 \mathrm{in}$ & 0.078 & Normal \\
\hline Additional Mass $\left(\boldsymbol{M}_{\text {add }}\right)$ & $100000 \mathrm{lb}$ & 0.1 & Normal \\
\hline Diameter $(\boldsymbol{D})$ & $12.3 \mathrm{in}$ & - & - \\
\hline Horizontal Element Length $(\boldsymbol{L} 1)$ & $118.11 \mathrm{in}$ & - & - \\
\hline Diagonal Element Length $(\boldsymbol{L} 2)$ & 167.0328 & - & - \\
\hline Density $(\boldsymbol{o})$ & $0.7 \mathrm{lb} / \mathrm{in}^{3}$ & - & - \\
\hline
\end{tabular}

This calculation will be simulated gradually, so it will be known displacement and reliability of the system at each stage of the simulation. The simulation results can be seen in Table 6 below:

Table 6. Results of Running Structure of Plane Truss Triangle Model Structure

\begin{tabular}{|c|c|c|c|c|c|c|}
\hline \multirow{2}{*}{$\begin{array}{c}\text { Number of } \\
\text { Simulation }\end{array}$} & \multicolumn{2}{|c|}{$\begin{array}{c}\text { Mean of } \\
\text { Displacement }\end{array}$} & \multirow{2}{*}{$\begin{array}{c}\text { Reliability } \\
\text { of System }\end{array}$} & $\begin{array}{c}\frac{\left(u_{v i}+1\right)-u_{v i}}{u_{y i}} \times \\
100 \%\end{array}$ & $\frac{\left(R_{i}+1\right)-R_{i}}{R_{i}} \times$ & \multirow{2}{*}{$\begin{array}{c}\text { CPU } \\
\text { Time }\end{array}$} \\
\cline { 2 - 7 } & $\mathbf{u x}$ & $\mathbf{u Z}$ & & $00 \%$ & \\
\hline 10000 & 0.015833 & 0.004963 & 0.702000 & 0.000632 & 0.001 & 143.607 \\
\hline 30000 & 0.015817 & 0.004958 & 0.854533 & 0.000632 & 0.001 & 426.201 \\
\hline 80000 & 0.015822 & 0.004959 & 0.874613 & 0.000632 & 0.001 & 1091.061 \\
\hline 100000 & 0.015818 & 0.004958 & 0.249420 & 0.000632 & 0.004 & 1452.644 \\
\hline 120000 & 0.015815 & 0.004957 & 0.202317 & 0.000632 & 0.005 & 1748.010 \\
\hline 150000 & 0.015829 & 0.004961 & 0.237560 & 0.000632 & 0.004 & 2181.845 \\
\hline 180000 & 0.015826 & 0.004960 & 0.233411 & 0.000632 & 0.004 & 2543.478 \\
\hline 200000 & 0.015825 & 0.004960 & 0.213390 & 0.000632 & 0.005 & 2809.365 \\
\hline
\end{tabular}

From the table, it can be plotted the relation of the number of simulations with displacement and the reliability that occurs. As shown in figure 5 below:

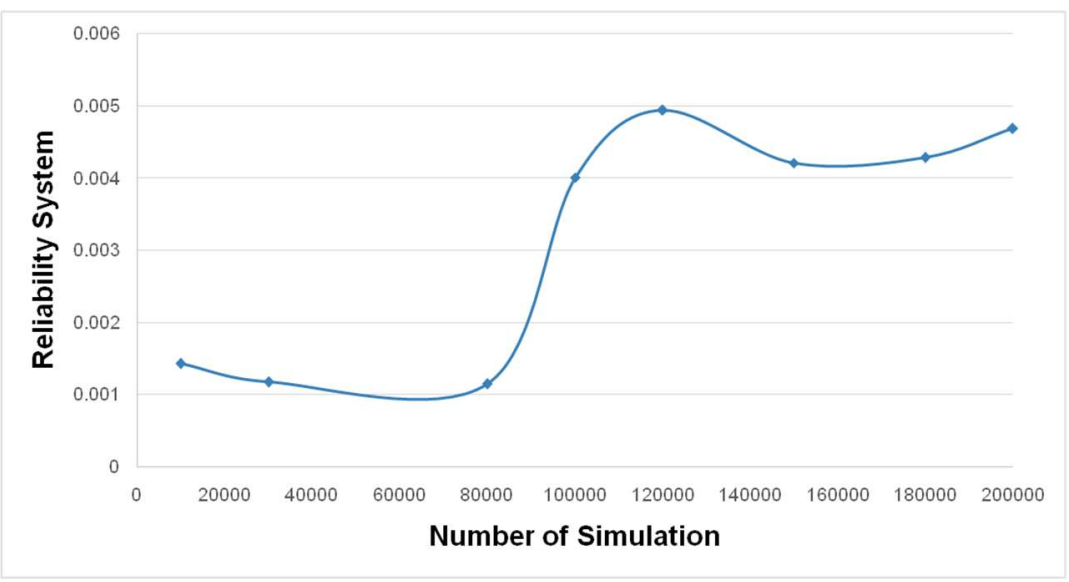

Fig. 5. Graph Relation between Simulation and Reliability 


\section{Conclusions}

Based on the explanation of Monte Carlo Simulation application on Finite Element Method for Dynamic Model of 2 Dimensional Simple Structure above, it can be concluded as follows:

1. The proposed software has been compared with commercial software by using time history method with Newmark Method numerical technique. It showed the tolerable error.

2. Application of MCFEM as the solution of dynamic model equation has been made by using the MCFEM algorithm in Plane Truss Triangle Model. It is obtained the reliability 0.213390 in 200,000 times of simulations.

\section{References}

1. Schueller, GI, Shinozuka, M. Stochastic Methods in Structural Dynamics (Dordrecht: Netherland, Marthinus Nijhoff Publisher, 1987)

2. Cherng, Rwey-Hua, Stochastic Finite Element Analyzes of Uncertain Nonlinear Plane Under Random Excitatitions (Urbana: Illinois. National Science Foundation, 1992)

3. Chapra, SC, Numerical Method for Engineer. 6th ed. (United States of America: McGraw-Hill, 2009)

4. Guoliang, J., Chen Lin \& Dong Jiamei, RESS, 40, 77 - 83

5. Koduru, SD \& Haukaas, T., Structural Safety, 32: 145-153, (2010)

6. Rosyid, DM, Pengantar Rekayasa Keandalan (Surabaya, Airlangga University Press, 2007)

7. Setiawan, A., Structural analysis, (Jakarta, Indonesia, Publisher Erlangga, 2015)

8. Campbell, SL, Modeling and Simulation in Matlab/Scicos with ScicosLab 4.4. 2nd ed, (London, Springer, 2010)

9. Chapra, SC, Numerical Method for Engineer. 6th ed (United States of America, McGraw-Hill, 2009)

10. Clough, Ray W \& Joseph Penzen, Dynamics of Structures, (Berkeley, USA, Computers \& Structures Inc, 2003)

11. Craig, Roy. Fundamental of Structural Dynamics (New Jersey: Canada. John Wiley, 2006)

12. Dymiotis, C., Reliability Based Calibration Code for Earthquake-Resistent Design, Edinburgh. JCSS Workshop on Reliability Based Code Calibration. (2001)

13. Ranganathan, R., Reliability Analysis and Design of Structures(Delhi, Tata McGraw Hill, 1990)

14. DNV RP G101, Risk Based Inspection of Offshore Topsides Static Mechanical Equipment, (Norway: DET NORSKE VERITAS, 2002)

15. Graduates, A., Setyo, Y., Rosyid, D, International Conference on Technology, Informatics, Management, Engineering \& Environment, Bandung: Indonesia, (2013) 